\section{ANÁLISE DE ALGUNS INSTRUMENTOS DE PARTICIPAÇÃO SOCIAL NA GESTÃO DOS RECURSOS HÍDRICOS}

\author{
Flávia Darre Barbosa ${ }^{1}$ \\ Maria Conceição Lopes ${ }^{2}$ \\ Salvador Carpi Junior ${ }^{3}$
}

\begin{abstract}
RESUMO
O artigo trata de discutir a participação social na Gestão dos Recursos Hídricos no Brasil, conforme diretrizes da Política Nacional de Recursos Hídricos. O objetivo do artigo é relatar experiências realizadas em dois projetos que aplicaram ferramentas da participação social, a fim de estabelecer a relação com níveis e categorias de participação, como forma de contribuir para a gestão dos recursos hídricos no Brasil. O primeiro projeto a ser relatado é o Mapeamento Ambiental ParticipativoExperiência TURVO/GRANDE, realizado via Comitê da Bacia Hidrográfica do Turvo/Grande (CBHTG), com base de trabalho na Apta Polo Regional Centro Norte, no ano de 2011. O segundo projeto é - Água: Conhecimento para Gestão, realizado em parceria da Fundação Parque Tecnológico Itaipu, Itaipu Binacional e Agência Nacional de Águas, com foco no curso Gestão de Recursos Hídricos: Metodologias de Participação Social ministrado entre outubro de 2013 a maio de 2015. Os projetos trabalham com as ferramentas de participação, entre elas: Mapeamento Ambiental Participativo, Diagrama de VENN e Oficina do Futuro. Como resultado foi possível verificar que os instrumentos aplicados promovem a participação social em interface de consulta e cooptação, nível médio de participação e estão de acordo com as diretrizes da Política Nacional dos Recursos Hídricos.
\end{abstract}

PALAVRAS-CHAVE: Participação Social, Gestão de Recursos Hídricos, Política Nacional de Recursos Hídricos.

\section{ANALYSIS OF SOME SOCIAL PARTICIPATION INSTRUMENTS IN WATER RESOURCES MANAGEMENT}

\begin{abstract}
The article comes to discussing social participation in Water Management in Brazil, according to the guidelines of the National Water Resources Policy. The aim of this paper is to report experiments on two projects that have applied tools of social participation in order to establish the relationship with levels and categories of participation as a way to contribute to the management of water resources in Brazil. The first project to be reported is the Environmental Mapping Collaborative- Experience cloudy / BIG conducted via the Watershed Committee of the Turvo / Grande (CBH-TG), based on work Fit Polo Regional Centro Norte, in 2011. The second project is the Water: Knowledge for Management, held in partnership with the Itaipu Technological Park Foundation, Itaipu and the National Water

\footnotetext{
${ }^{1}$ Doutoranda no programa de Pós-Graduação em Ciências Ambientais na UFSCar. Professora no Projeto Água: Conhecimento para Gestão- FPTI, PTI e ANA.

${ }^{2}$ Bióloga, mestra em Agronomia, Ciência do Solo. Oficial de Apoio à Pesquisa Cientifica/ APTA/SAA

${ }^{3}$ Geógrafo, Doutor em Geociências e Meio Ambiente. Pesquisador, Instituto de Geociências/UNICAMP
} 
Agency, focusing on the ongoing Water Resources Management: Social Participation methodologies taught from October 2013 to May 2015. The projects work with the tools participation, including: Collaborative Environmental Mapping, VENN diagram and Future Shop. As a result we found that the applied instruments promote social participation in consultation and co-option interface, average level of participation and are in accordance with the guidelines of the National Water Resources Policy.

KEYWORDS: Social Participation, Water Resources Management, National Water Resources Policy.

\section{ANÁLISIS DE ALGUNOS INSTRUMENTOS DE PARTICIPACIÓN SOCIAL EN LA GESTIÓN DE LOS RECURSOS HÍDRICOS}

\section{RESUMEN}

El artículo trata de discutir la participación social en la Gestión del Agua en Brasil, de acuerdo con las directrices de la Política Nacional de Recursos Hídricos. El objetivo de este trabajo es reportar experimentos en dos proyectos que han aplicado herramientas de participación social con el fin de establecer la relación con los niveles y categorías de participación como una forma de contribuir a la gestión de los recursos hídricos en Brasil. El primer proyecto que se informó es la Experiencia Ambiental Cartografía Participativo- nublado / BIG realizada a través del Comité de Cuenca del Turvo / Grande (CBH-TG), basado en el trabajo Fit Polo Regional de Centro Norte, en 2011. El segundo proyecto es el agua: Conocimiento para la Gestión, que se celebró en colaboración con la Fundación Parque Tecnológico Itaipú, Itaipú y la Agencia Nacional del Agua, centrándose en la gestión de los recursos hídricos en curso: metodologías de participación social que se enseñan desde octubre 2013 a mayo 2015. Los proyectos de trabajo con la participación herramientas, incluyendo: Cartografía Ambiental Participativa, diagrama de Venn y Future Shop. Como resultado, se encontró que los instrumentos aplicados promover la participación social en la consulta y la co-opción de interfaz, nivel medio de participación y están en conformidad con las directrices de la Política Nacional de Recursos Hídricos.

PALABRAS CLAVE: Participación Social, Gestión de Recursos Hídricos, la Política Nacional de Recursos Hídricos.

\section{INTRODUÇÃO}

Quando se instituiu a Política Nacional de Recursos Hídricos- PNRH- no Brasil, através da Lei 9.433 em 1997 (Lei Federal, Presidência da República, 1997), conhecida como a "Lei das Águas", além da contribuição para a Gestão dos Recursos Hídricos no país, foi dado também mais um passo fundamental em direção a democracia e desenvolvimento da cidadania, uma vez que esta lei incorporou a participação social na gestão destes recursos, como aponta 0 artigo $1^{\circ}$, dos Fundamentos da Política Nacional de Recursos Hídricos (PNRH), onde lê-se no inciso: VI - a gestão dos recursos hídricos deve ser descentralizada e contar com a participação do Poder Público, dos usuários e das comunidades.

Para tanto, foi estabelecido que, o Sistema Nacional de Gerenciamento de Recursos Hídricos, que implementa a PNRH, deve ser composto, entre outros 
órgãos e agências, pelos Conselhos, Nacional e Estadual de Recursos Hídricos e por Comitês de Bacias Hidrográficas. Tais organismos colegiados possuem diversas funções, dentre elas se destaca a função de instância política- administrativa que irá intermediar as relações entre Federação, Estado e Município. Abarcam em sua composição representantes do poder público, usuários de água e sociedade civil. Tais atores possuem a missão de articular o diálogo entre e dentro dos organismos, e estender o mesmo à comunidade, promovendo a participação social.

Os resultados obtidos nestes diálogos são a base, no contexto da gestão dos recursos hídricos, para a formulação dos Planos Nacionais de Recursos Hídricos e Planos de Bacias, onde serão dadas as diretrizes para o planejamento das bacias hidrográficas e gestão da água.

Contudo, perante tal quadro de gestão, faz-se necessário (re)pensar os instrumentos que tais colegiados possam utilizar para promover a mobilização e participação social de maneira mais efetiva a contribuir com os Planos, bem como (re)pensar também o significado e os objetivos da própria participação social.

Sobre o conceito de participação social, cabe ressaltar que, conforme aponta Evans (2012):

\begin{abstract}
"É a maneira pela qual as aspirações e as necessidades dos diferentes segmentos da população podem ser expressas no espaço público de forma democrática, e não limitada apenas pelo voto. Além disso, está associada ao modo como esses "grupos" se percebem como cidadãos e cidadãs. Além disso, a participação é um processo educativo. Expressar desejos e necessidades, construir argumentos, formular propostas, ouvir outros pontos de vista, reagir, debater e chegar ao consenso são atitudes que transformam todos/as aqueles/as que integram processos participativos". (EVANS, in MPOG 2012. p.10)
\end{abstract}

Então a priori, a participação social já é dotada de valor em si mesma e deve ser compreendida como um processo de construção política-cultural-social, que passa pela esfera educacional. Sendo assim, não existe apenas uma única forma de participação, já que ela não é o fim, e sim o meio de transformação social. É comum encontrar diversos autores que falam de níveis de participação social que são heterogêneos e variam de acordo com a política e objetivos pretendidos quando são aplicados métodos de participação específicos.

Souza (2004) propõe uma escala para a participação social, dividida em oito categorias, que variam de simples manifestações públicas, até a participação autêntica representada pela categoria Autogestão. As categorias são, 
1- Coerção.

2- Manipulação

3- Informação

4- Consulta

5- Cooptação

6- Parceria

7- Delegações de poder

8- Autogestão

As três primeiras categorias representam um baixo nível de participação, uma vez que a população não possui nenhum poder de decisão. As categorias $4 \mathrm{e}$ 5 , já abarcam um nível médio de participação, onde a população participa de parte do processo público quando é consultada e representada por instâncias participativas. As três últimas categorias podem ser consideradas como o nível alto de participação, pois a população já possui alto poder de decisão nas questões públicas através das parcerias, chegando ao nível máximo da autogestão- onde o Estado está praticamente ausente das decisões tomadas.

Outros autores, como BORDENAVE e FEDOZZI (Conferência, 2011) falam em escalas de participação, que seriam da informação, cogestão e autogestão, e que podem ser espontâneas, impostas, voluntárias, provocadas e concedidas.

Bordenave discorre sobre três dimensões que precisam ser consideradas: fazer parte; tomar parte; e ter parte. "De fato, a palavra participação vem da palavra parte. Participação é fazer parte, tomar parte ou ter parte" (BORDENAVE, 1994, p. 22). Conforme o IPEA, os níveis de participação podem ser expressos em interfaces entre governo e sociedade civil, sendo,

\begin{abstract}
Interfaces cognitivas: que reclamam um caráter mais comunicacional em relação ao Estado, que se dividem em: interface de contribuição: na qual a sociedade informa ao Estado acerca de sugestões ou demandas; interface de transparência: na qual o Estado informa à sociedade suas perspectivas e ações; interface comunicativa: na qual ambos os atores se informam mutuamente.

Interfaces políticas: ligada a perspectiva de gestão e enforcement de políticas, sendo a sua expressão mais explícita a interface de cogestão, na qual os processos decisórios são compartilhados entre ambos os atores.
\end{abstract}

(IPEA. Sem data)

Com certeza existem muitas outras considerações e estudos sobre formas de participação, porém, tal discussão ficaria muito extensa para o presente artigo. Assim, é com base nas reflexões que foram colocadas que pretende-se estabelecer o diálogo deste estudo. 
Considerando os instrumentos de participação social que estão sendo utilizados no âmbito da PNRH e planos de bacias e que serão apresentadas neste artigo através de dois projetos é possível estabelecer de antemão que os mesmos atuam na interface cognitiva, principalmente na contribuição, e na categoria "consulta", uma vez que se utilizam de canais de Audiências Públicas e Consultas Públicas para captar informações acerca da situação dos recursos hídricos contribuindo tanto para o diagnóstico da bacia hidrográfica, quanto para a própria educação ambiental.

Carpi Jr et al (2014) apontam que existem ferramentas de participação social que trazem muitos benefícios e ótimos resultados, entre eles a prevenção de situações de riscos nas bacias hidrográficas, e por isso são adequadas para serem utilizadas por comitês de bacias, como é o caso do Mapeamento Ambiental Participativo (MAP), que será tratado neste artigo.

Com relação aos Conselhos de Bacias e Comitês de Bacias, são eles próprios representantes de iniciativas de atuação com interface política, na categoria de cooptação.

Portanto, com o exposto, está apresentada a importância de discutir o espaço que ocupa a participação social na gestão dos Recursos Hídricos no Brasil, e que vem ocorrendo junto ao processo de democratização política. Nesse contexto, o objetivo deste presente artigo é relatar experiências realizadas em dois projetos que trabalham alguns instrumentos de participação social, a fim de estabelecer a relação destes com os níveis e categorias de participação como forma de contribuir para a gestão dos recursos hídricos no Brasil.

\section{METODOLOGIA}

Para alcançar o objetivo proposto, são apresentados dois projetos que promovem, e ao mesmo tempo discutem e trabalham com alguns instrumentos de participação social desenvolvendo atividades de capacitação a um público alvo de educadores, gestores que trabalham nas esferas estaduais e municipais, profissionais que atuam na área, sociedade civil organizada e os membros Conselhos e Comitês de Bacia Hidrográfica, principalmente para os que se encontram no início de suas atividades.

O primeiro é a capacitação técnica "Mapeamento Ambiental Participativo: Experiência de Educação Ambiental na Bacia Hidrográfica Turvo e Grande- BH-TG" e o 


\section{Periádica Eletranica

segundo é o projeto "Água: Conhecimento para Gestão", com destaque para o curso Gestão de Recursos Hídricos: Metodologias de Participação Social”.

\subsection{O MAPEAMENTO AMBIENTAL PARTICIPATIVO- PROJETO TURVO-GRANDE}

Este projeto é uma iniciativa das diretrizes da capacitação de educadores do projeto de educação ambiental "Bacia Hidrográfica: Um Instrumento na Educação" FEHIDRO TG 350/2009, que foi realizado via Comitê da Bacia Hidrográfica do Turvo/Grande (CBH-TG), com base de trabalho na Apta Polo Regional Centro Norte, no ano de 2011.

Segundo Martins e Lopes (2011) o Polo Regional Centro Norte, órgão da Agência Paulista de Tecnologia dos Agronegócios (APTA) é vinculada à Secretaria de Agricultura e Abastecimento da Agricultura (SAA) e está localizado no Município de Pindorama, um dos municípios integrantes do comitê de bacias hidrográfica dos Rios Turvo e Grande (CBH-TG).

O Polo pode ser considerado referência de prática conservacionista do solo e centro de capacitação de educadores, atuando em parceria CBH-TG e instituições de ensino e outras entidades. Além disso, mobiliza as Diretorias de Ensino Regionais do Interior - DER e Secretaria Municipais de Educação.

Lopes et al (2014) discorre que o projeto de Mapeamento Ambiental Participativo foi realizado em Julho de 2011, como forma de capacitação técnico/pedagógica denominada "Identificação de riscos e alterações ambientais em Bacias Hidrográficas".

Participaram da capacitação 55 educadores e técnicos ambientais integrantes de 11 municípios da bacia dos rios Turvo e Grande, a saber: Ariranha, Fernandópolis, Mirassol, Guapiaçu, Catanduva, Olímpia, Orindiúva, Santa Adélia, Tanabi, Pindorama. Primeiro foi realizada uma palestra técnica referente aos conceitos de bacia hidrográfica, riscos ambientais e sobre o método do Mapeamento Ambiental Participativo (MAP).

O Mapeamento Ambiental Participativo é uma ferramenta que está sendo cada vez mais utilizada nos estudos relativos a bacias hidrográficas e sua essência é a participação social, pois, através de reuniões públicas a comunidade aponta em base cartográfica previamente elaborada, as diversas situações encontradas na bacia e no local onde vivem. Portanto, além da educação ambiental intrínseca ao 


\section{Periádica Eletranica

método, a comunidade constrói um diagnóstico da bacia hidrográfica, que posteriormente pode ser verificado por técnicos ligados aos comitês e conselhos de bacias sendo útil a elaboração do plano de bacia.

No projeto mencionado, a metodologia, segundo discorre Carpi $\mathrm{Jr}$ et al. (2014), deu-se da seguinte forma: foram distribuídos os mapas base de cada município envolvido aos participantes, e também um mapa geral de toda a bacia Turvo e Grande, representada pela UGRHI $15^{4}$. Os mapas-base foram elaborados a partir do material cartográfico cedido pelo CBH-TG (IPT, 1999).

A partir da distribuição, foram formados grupos conforme o município de origem. Cada grupo recebeu seu mapa base e junto um roteiro um roteiro básico de identificação de riscos, para facilitar e fomentar a participação. Partindo do seu conhecimento e percepção sobre o meio, os participantes, indicaram no mapa-base, com auxílio de canetas hidrográficas coloridas, em quais áreas ocorriam situações de riscos ambientais e em quais apareciam os aspectos ambientais positivos ou suas potencialidades.

A finalização da capacitação foi feita através da apresentação dos mapas, onde cada grupo comentou sobre suas percepções e as características de cada município e sobre o que foi mapeado.

Posteriormente, os mapas com os apontamentos foram recolhidos pela equipe organizadora, para compilação dos dados, organização e digitalização do material cartográfico e textual. Para tanto utilizou-se o programa CoreIDRAW, atentando a questão de precisão cartográfica, pois, uma vez que as informações foram apontadas pela comunidade, procurou-se manter o mais fiel possível estes apontamentos ao reproduzi-los para as bases cartográficas finais, ressaltando que seria interessante realizar trabalhos posteriores para confirmação de dados, como confirmação in loco e outros levantamentos para manter atualizada a pesquisa.

E para apresentar parte do resultado deste projeto, foi selecionado pelos autores deste artigo dentre os 12 mapas elaborados que estão disponíveis em Carpi Jr et al (2014), o Mapeamento Ambiental Participativo do município de Santa Adélia.

${ }^{4}$ Segundo o IPT(1999), a Bacia Hidrográfica do Turvo/Grande foi definida como a Unidade Hidrográfica de Gerenciamento de Recursos Hídricos 15 (UGRHI-15) pela Leinํ․034/94, de27/12/1994, que dispôs sobre o Plano Estadual de Recursos Hídricos para o biênio1994/95. 


\section{Periódica Eletrânica

(Figura 01), por apresentar uma situação de risco potencial em 2011, que se transformou em desastre ambiental.

Figura 01: Mapeamento Ambiental Participativo- Município de Santa Adélia Fonte: CARPI Jr et al. 2014.

Tal situação, que está representada pelo símbolo de "Estrela Vermelha" no mapa, foi apontada em 2011 pela comunidade que participou do projeto como área de risco ambiental, por ali estarem localizados galpões da Usina de Açúcar e Álcool do município.

Em 25 de Outubro de 2013, um incêndio no Galpão de Açúcar no terminal
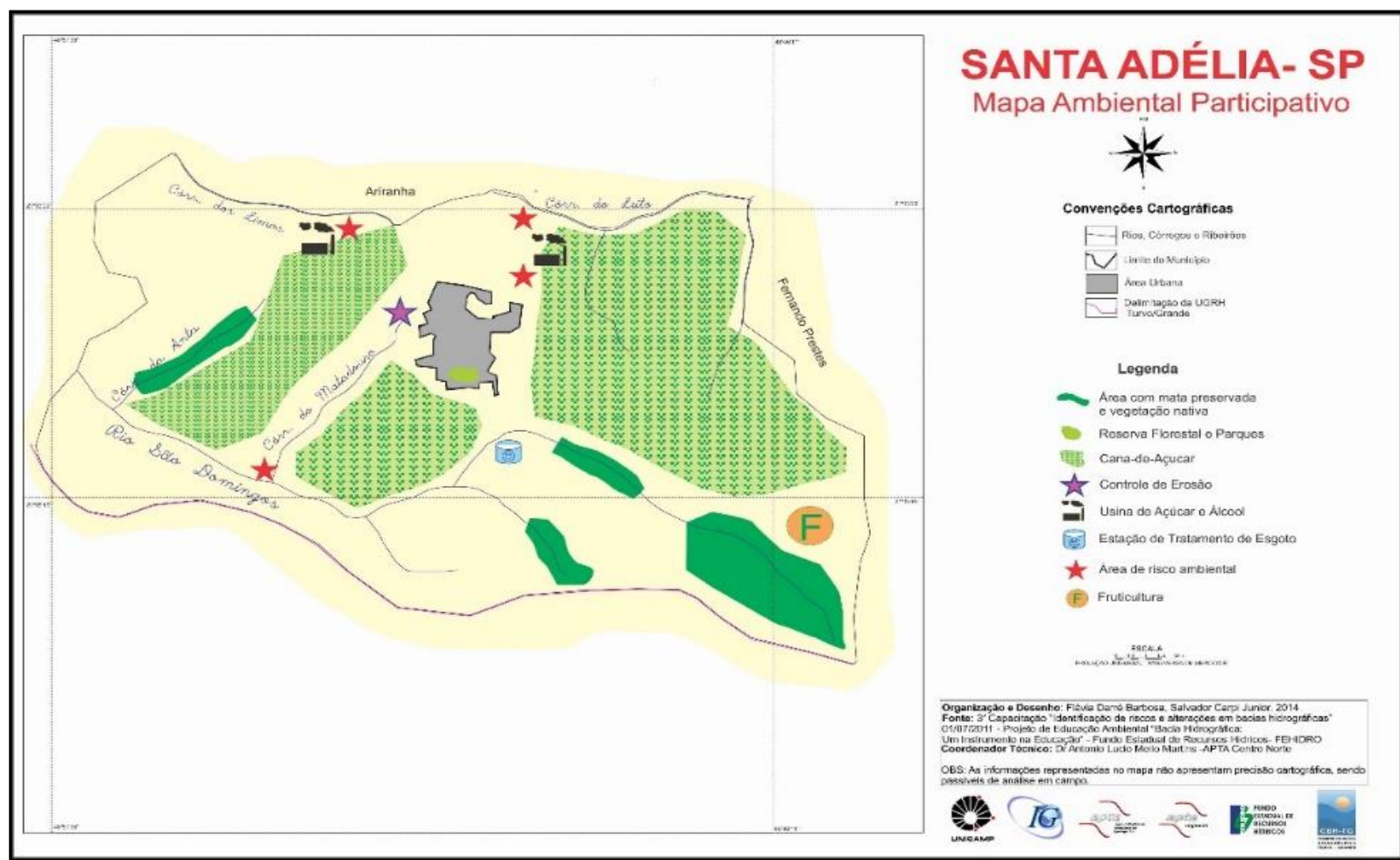

da Usina Santa Adélia, causou um grande desastre Ecológico no Rio São Domingos, que nasce em Santa Adélia e deságua no rio Turvo, atingido diversos municípios, conforme informações disponíveis em: www1.folha.uol.com.br/.

Com este exemplo retirado do trabalho na bacia do Turvo/Grande, ressaltase a importância do instrumento de Mapeamento Ambiental Participativo para, entre outras coisas, diagnosticar áreas de risco, conforme dito anteriormente e assim realizar o apontamento destas situações para que sejam consideradas pelos 
Conselhos, Comitês e Órgãos Gestores dos Recursos Hídricos na construção do plano de gestão.

Além disso, os participantes da capacitação passaram por uma etapa do processo de educação ambiental quando observaram a bacia hidrográfica em que estão inseridos, e perceberam a situação ambiental, política e econômica que compõem o território.

\subsection{EXPERIÊNCIAS NO PROJETO "ÁGUA: CONHECIMENTO PARA GESTÃO"- CURSO: METODOLOGIAS DE PARTICPAÇÃO SOCIAL}

O projeto "Água: Conhecimento para Gestão" ${ }^{5}$ nasceu de uma parceria entre a Agência Nacional das Águas e a Fundação Parque Tecnológico Itaipu, com o apoio da Itaipu Binacional no ano de 2011, e conforme o Ministério do Meio Ambiente (MMA, 2006) in Revista Água e Gestão (2014), "a iniciativa atende ao Plano Nacional de Recursos Hídricos no que tange o desenvolvimento tecnológico, capacitação, comunicação e difusão de informações em Gestão integrada de Recursos Hídricos". (MMA, 2006 in Revista Água e Gestão, 2014.p.3)

São 34 cursos ofertados, e o público alvo do projeto, que já alcançou todos os países da América Latina, são pessoas envolvidas diretamente com o Sistema Nacional de Gerenciamento de Recursos Hídricos ${ }^{6}$, como os membros de comitês de bacias, órgãos gestores, agências de água, ONGs, conselhos de recursos hídricos entre tantos outros atores.

Um dos cursos do projeto é o de "Gestão de Recursos Hídricos: Metodologias de Participação Social”. De forma geral este curso, que é semipresencial,

\footnotetext{
"trabalha conhecimentos, habilidades e atitudes que visam estimular a mobilização, construção coletivo, mediação de conflitos e o planejamento participativo dos atores atuantes na gestão dos Recursos Hídricos". (Revista Água e Gestão, 2014.p.10)
}

O curso, que é dividido em momento à distância (EaD) e momento presencial, foi escolhido para ser apresentado neste artigo por conta dos instrumentos de participação social que estão sendo utilizados em aulas e seus desdobramentos, como forma de contribuir com a gestão dos recursos hídricos, conforme a PNRH.

Foi realizado em vários Estados do Brasil, desde 2013 até maio de 2015, a saber: São Paulo, Minas Gerais, Distrito Federal (Brasília), Rio Grande do Sul, Rondônia, Acre,

\footnotetext{
${ }^{5}$ Mais informações sobre o projeto Água: Conhecimento para Gestão, e sobre o curso de Metodologias de Participação Social acessar: www.aguaegestao.com.br

${ }^{6}$ O Sistema Nacional de Gerenciamento de Recursos Hídricos (SINGREH), criado pela Lei no 9.433/97, estabeleceu um arranjo institucional claro e baseado em novos princípios de organização para a gestão compartilhada do uso da água. Mais informações:

http://www.planalto.gov.br/ccivil 03/leis/19433.htm
} 


\section{Periódica Eletranica

Santa Catarina, Paraná, Rio Grande do Norte, Ceará e Mato Grosso do Sul; sendo previsto para outros Estados.

Em cada Estado onde foi ministrado o curso até a redação deste artigo, a realidade na gestão dos recursos hídricos em relação à Política (Nacional e Estadual) de Recursos Hídricos se apresenta de maneira distinta, por conta do contexto cultural-socioeconômico e político de cada região. No Acre, por exemplo, ainda não existem os Comitês de Bacia Hidrográfica, previstos na Política Nacional de Recursos Hídricos. A Gestão está integrada à Secretaria de Meio Ambiente e a fase atual corresponde à implementação do Plano Estadual de Recursos Hídricos, que data de 2012, através principalmente do Conselho Estadual de Recursos Hídricos.

No norte do Estado do Paraná a gestão e o planejamento estão avançados com relação aos instrumentos da Política Nacional de Recursos Hídricos, uma vez que juntamente com o pontal do Paranapanema no Estado de São Paulo estão construindo o Plano Integrado de Recursos Hídricos do Paranapanema. Seis comitês de bacia estão sendo articulados, sendo 3 (três) do Estado de São Paulo e 3 (três) do Paraná, todos pertencentes ao eixo do Paranapanema.

Embora existam diferenças regionais e de gestão, as ferramentas de participação social foram aplicadas com o mesmo procedimento metodológico em todas as turmas, e apesar de o curso ter como objetivo pedagógico a capacitação, tais ferramentas também serviram de base para a discussão e diagnóstico das respectivas bacias hidrográficas em cada Estado, ressaltando que, em todas as turmas a metodologia é trabalhada conforme o contexto de cada região, facilitando e fomentando as discussões durante o as reuniões.

Para tanto, no momento presencial os alunos são divididos em grupos para trabalhar com as ferramentas, que são aplicadas de forma transversal utilizando a participação social como base de discussão. São elas: Semáforo de Riscos, Diagrama de Venn, Mapeamento Ambiental Participativo (adaptado), Perfil Hidroambiental realizado em trabalho de campo, Quadro de Situação/Diretrizes e Oficina do Futuro.

Como exemplo foi selecionado para o presente artigo o curso ministrado em Rondônia, e, a figura 02 mostra o resultado do procedimento metodológico utilizado no momento presencial e apresentado por 1 (um) dos 6 (seis) grupos formados durante as aulas. Na figura é possível notar as etapas de trabalho com as ferramentas de participação social que serão descritas a seguir. 
Figura 02: Apresentação de resultado de um dos grupos da Turma de Porto Velho- Rondônia

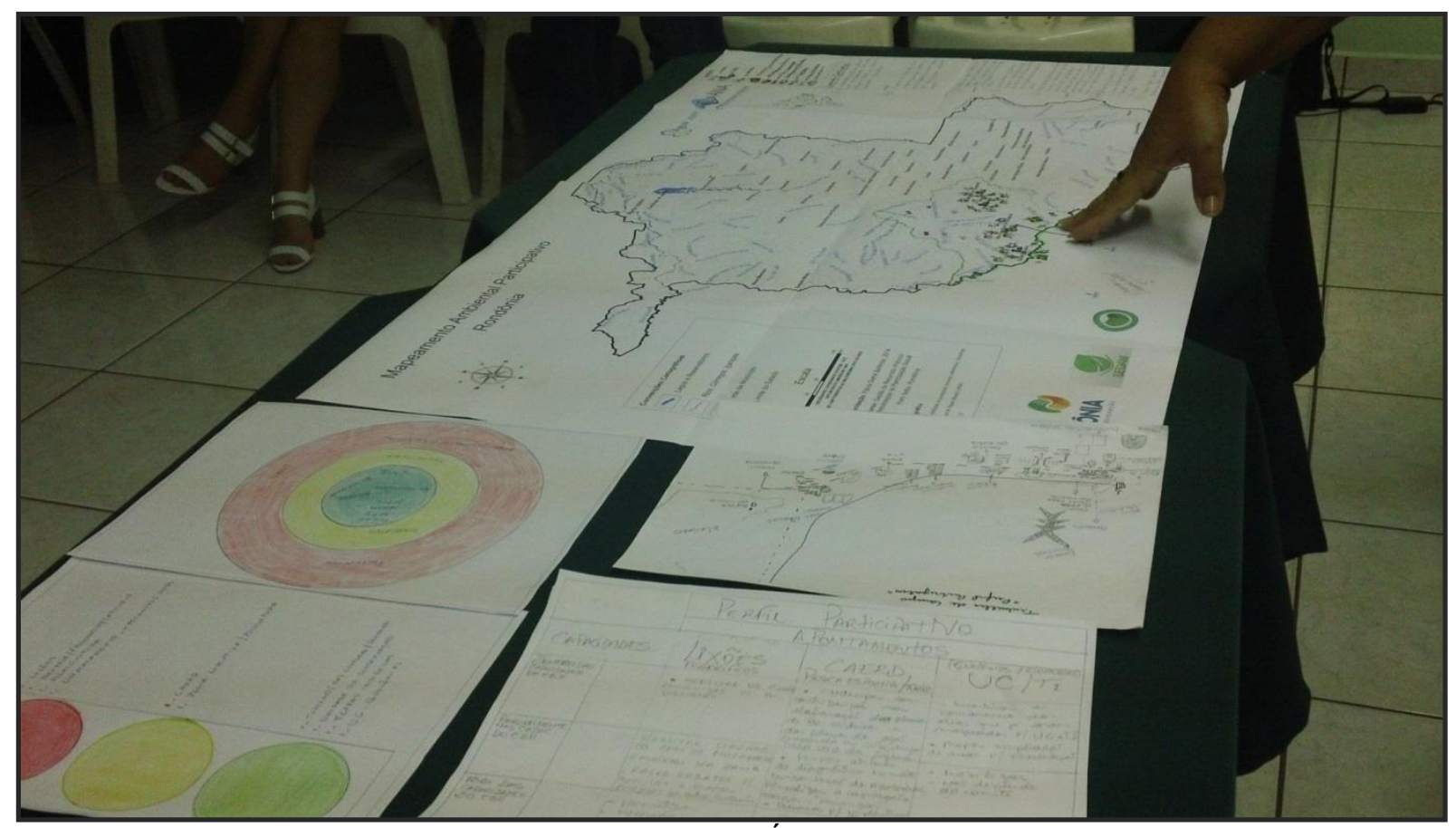

Foto: Rubiana Dias de Oliveira, equipe do Projeto Água e Gestão, 2014

Vale ressaltar que, no momento do curso o Estado de Rondônia não possuía Comitês de Bacia Hidrográfica, e a metas de gestão estavam como responsabilidade do Conselho Estadual de Recursos Hídricos e por este motivo as bases cartográficas procuraram atender ao Estado de forma integrada. O curso contou com a participação de membros do órgão gestor do Estado, membros do Conselho, representantes da sociedade civil como instituições, ONGs entre outros, totalizando 47 participantes.

Em todos os cursos, como etapas do trabalho, primeiro os participantes recebem a base cartográfica, onde apontam diversas situações encontradas na bacia, desde situações de riscos até o perfil econômico do território e do uso e ocupação. Apontam as situações no mapa, utilizando de cartográfica temática. Os apontamentos são passados para uma legenda explicativa. As bases cartográficas são previamente preparadas, levando-se em consideração os contextos dos recursos hídricos locais e regionais, de forma que a discussão seja trazida para o âmbito real.

Em sequência os grupos estabelecem o semáforo de riscos distribuindo o que identificaram no mapa em três situações: Vermelho, Amarelo e Verde, onde o Vermelho indica situação de alto risco ou impacto já ocorrido; Amarelo, atenção para 


\section{Periódica Eletranica

a situação que pode vir a ser um impacto; Verde- situação com baixo risco e/ou nenhum impacto.

Então fazem o diagrama de VENN, quando (re)pensam a atuação dos órgãos e instituições presentes no Estado que possuem alguma relação com a gestão da água na bacia hidrográfica. Conforme o grau de atuação, o órgão ou instituição é colocado mais próximo do centro do diagrama.

A etapa do trabalho de campo pode servir para conferir in loco o que foi diagnosticado no mapeamento ambiental. Porém, no curso, como não existe a possibilidade de realizar os trabalhos em todas as bacias analisadas, escolhe-se uma área local para a realização do Perfil Hidroambiental.

No caso de Rondônia o roteiro do Perfil Hidroambiental, foi realizado acompanhando o Rio Madeira, desde a Usina Hidrelétrica de Santo Antônio até a área urbana de Porto Velho. Vale ressaltar que no momento da realização do curso em 2014, a região estava afetada pela enchente histórica do Rio Madeira ${ }^{7}$. Os pontos de alagamento por conta de enchente foram apontados no perfil, além de outras percepções relevantes.

Na próxima etapa metodológica, os participantes recebem uma matriz onde, como membros do SINGREH e a partir do material que elaboraram com os instrumentos propostos, fazem colocações a respeito do que foi levantado em relação à gestão da água no Estado, pensando nas diretrizes e planos de bacia. Utilizam este momento para realizar discussões importantes a partir das realidades observadas.

O último instrumento de participação é a Oficina do futuro, com três etapas: Muro das Lamentações, Árvore dos Sonhos e Caminho Adiante. Os participantes neste momento refletem sobre as preocupações e possíveis ações práticas sobre a Gestão dos Recursos Hídricos.

Desta forma, o resultado da capacitação vai além da Educação Ambiental, pois serve como base para futuros planejamentos a respeito dos Recursos Hídricos de cada região, sendo reaproveitados por membros dos Conselhos, Comitês entre outras instâncias de gestão.

${ }^{7}$ Sobre a enchente do Rio Madeira, acessar: http://g1.globo.com/ro/rondonia/noticia/2014 


\section{DEBATE SOBRE OS RESULTADOS}

Com o intuito de estabelecer as relações dos projetos apresentados com níveis e categorias de participação social apresentados na introdução do presente artigo e pensando na contribuição para a gestão dos Recursos Hídricos, é possível estabelecer que o PROJETO TURVO-GRANDE, demonstra que o Mapeamento Ambiental Participativo é um instrumento de participação social que promove, além da educação ambiental, um diagnóstico fundamental de uma bacia hidrográfica, levando em consideração o conhecimento e percepção de quem reside no interior da bacia.

Sobre o CURSO DE METODOLOGIAS DE PARTICIPAÇÃO SOCIALPROJETO ÁGUA E GESTÃO pode-se assinalar que, além de capacitados para multiplicar as ferramentas de participação apresentadas durante o curso, ao final de cada turma, os participantes também têm um diagnóstico, elaborado de forma participativa, a ser utilizado na gestão dos recursos hídricos e nos planos de bacias de sua região.

Ambos os projetos assumem a participação social como foco principal na gestão das bacias hidrográficas, estando de acordo com a Política Nacional de Recursos Hídricos. Além disso, podem ser considerados com médio nível de participação, uma vez que são categorias de consulta e cooptação, e trabalham na interface cognitiva: contribuição e comunicação. Contribuição, pois, os participantes dos projetos puderam colaborar na gestão dos recursos hídricos à medida que forneceram dados das situações de suas respectivas bacias.

A interface comunicativa de participação aparece à medida que, nos dois projetos havia participantes do poder público, sociedade civil e usuários que dialogaram com o intuito de construírem junto um plano de ação.

A consulta está na mesma forma de participação do que a interface cognitiva de contribuição, onde os participantes através das reuniões e curso puderam fornecer um diagnóstico de situação da sua respectiva bacia hidrográfica, utilizando seu conhecimento e percepção, além de ser relevante para a Educação Ambiental.

A interface política de participação e a categoria de cooptação aparecem com o desenvolvimento dos projetos descritos, porém não estão ligadas diretamente aos métodos de participação. $\mathrm{Na}$ realidade, estão relacionadas com a própria 


\section{Periádica Eletranica

estrutura dos colegiados. A interface política e a cooptação acontecem entre os participantes nos projetos, na medida em que estes fazem parte de um Comitê de Bacia, Conselho (entre outros) que estão diretamente ligados ao Sistema Nacional de Gerenciamento de Recursos Hídricos.

Os projetos tratam de cogestão, à medida que os participantes são parte, fazem parte e tomam parte na Gestão de Recursos Hídricos de seus territórios quando realizam o diagnóstico utilizando os instrumentos de participação social citadas.

\section{CONCLUSÃO}

Após a breve análise dos projetos apresentados e sua relação com as categorias e interfaces da participação social, considerando os contextos regionais e a atual conjuntura da Política Nacional dos Recursos Hídricos no Brasil, é possível concluir que as ferramentas (métodos) aplicadas estão de acordo com as principais diretrizes "legais", sendo úteis principalmente para fornecer os diagnósticos e situações das bacias hidrográficas, que servirão de base para a gestão dos recursos hídricos e planos de ação.

Os projetos também cumprem com as metas do Plano Nacional de Recursos Hídricos, quando promovem a Educação Ambiental e Capacitação aos atores envolvidos na gestão destes recursos.

\section{REFERÊNCIAS}

BORDENAVE, J, E, Díaz. O que é participação. São Paulo: Ed. Brasiliense, 1994.

BRASIL PLANALTO. CASA CIVIL. Subchefias para Assuntos políticos. Lei 9.433. Disponível em: http://www.planalto.gov.br/ccivil 03/leis/19433.htm Acesso: 20 de Abril de 2015.

BRASIL. Ministério do Planejamento, Orçamento e Gestão (MPOG)- Diálogos Setoriais União Europeia - Brasil. PROJETO APOIO AOS DIÁLOGOS SETORIAIS UNIÃO EUROPEIA - BRASIL. RELATÓRIO PARTICIPAÇÃO SOCIAL NA ADMINISTRAÇÃO PÚBLICA FEDERAL: DESAFIOS E PERSPECTIVAS PARA A CRIAÇÃO DE UMA POLÍTICA NACIONAL DE PARTICIPAÇÃO. 2012

CARPI JUNIOR, S; LOPES, M.C.; BARBOSA, F. D.; MARTINS, A.L. MAPEAMENTO AMBIENTAL PARTICIPATIVO: EXPERIÊNCIA DE EDUCAÇÃO AMBIENTAL NA UGRHI TURVO E GRANDE. In: DIAS, L.S.; BENINI, S.M. (Org.). Estudos ambientais aplicados em bacias hidrográficas. 1ed.Tupã-SP: ANAP, 2014, v. 1, p. 29-57. Disponível em: www.amigosdanatureza.org.br/livros/livro/cod/86. Acesso em 19 de maio de 2015. 
EVANS, M; FERRAREZI, E; OLIVEIRA, C.G; GRAU, N.C. Participação social: textos para Discussão. In Inovação para a Gestão Pública. Cooperação Brasil- Espanha. Ministério do Planejamento, Orçamento e Gestão. Caderno 6. Ed.IABS: Brasília. 2013.

FEDOZZI, L. Inclusão dos cidadãos na implementação de Políticas Públicas no Brasil. In Seminário Internacional. Conferência em Brasília, 2011.

LOPES, M.C; CARPI JUNIOR, S; BARBOSA, F,D; MARTINS, A.L.M. Mapeamento Ambiental Participativo: Experiência de Educação Ambiental na UGRHI Turvo e Grande. DIÁLOGO INTERBACIAS DE EDUCAÇÃO AMBIENTAL EM RECURSOS HÍDRICOS, XII, 2014, São Pedro (SP). Caderno de resumos. XII Diálogo Interbacias de Educação Ambiental em Recursos Hídricos, 2014. São Pedro (SP), p.44.

MARTINS, A.L.M; LOPES, M.C; ABDO, M.T.V; Nogueira; VALARETTO, R.S. Educação Ambiental no Polo Regional Centro Norte Promove Ações de Sustentabilidade Regional. Pesquisa \& Tecnologia, 012011.20 Disponível em: http://www2.aptaregional.sp.gov.br/images editor/55.AntonioMartins EducacaoAmbiental.pdf Acesso em 27 de abril de 2015

PTI, Parque Tecnológico Itaipu; ITAIPU Binacional, ANA, Agência Nacional das Águas. Revista Água e Gestão. Projeto Água: Conhecimento para Gestão. 1ª Edição. 2015.

SOUSA, M,L. Mudar a Cidade- Uma introdução crítica ao planejamento e á Gestão Urbanos. Ed Bertrand Brasil. 2001. 